\title{
ADVANCES IN FIRE PROTECTION METHODS AND EQUIPMENT
}

\author{
By C. R. Mills
}

The subject of "Forest Fire Protection" has been cussed and discussed so often and so thoroughly that we are perhaps inclined to think of it as capable of no new developments. While the principle followed by the different protective organizations may be the same there are many modifications of it. We find particularly a tendency on the part of all to specialize in the use of mechanical devices, following the general trend of present day methods in an effort tol cut down the man power necessary.

Commencing on the Pacific Coast and working eastwards new features in forest fire protection as submitted by the different services and organizations will be briefly outlined.

\section{BRITISH COLUMBIA FOREST BRANCH.}

Radio Telephony-Considerable satisfaction has been obtained operating one central receiving agency fitted with a 300 watt transmitter, and six launches and one ranger station fitted with 100 watt sets.

Smoke Chasers Outfits-In connection with the lookout system a compact smoke-chaser's outfit has been developed for back-packing which without the fire fighting tool weighs $27 \mathrm{lbs}$.

This outfit consists of a cooking outfit, rations for two or three days and bedding all assembled on a light packboard.

The combination tool carried by the smoke-chaser consists of a singlebitted axe of special design with a perforated poll. Into this axe may be fitted a shovel, light mattock and a pick. The tool weighs $71 / 2 \mathrm{lbs}$.

Boats-A new type of lake and river boat has been put into service, which is of the light-draft speed type operated by an outboard motor and makes up to sixteen miles an hour. This is provided with locker seats in the bow under which the motor and other equipment may be stored.

Fusees-Ordinary railway fusees have been used effectively for back firing.

Nobymo-A fire deterrent with the trade name "Nobyrno" has been used with good success. The liquid is carried in five gallon hand-tank pumps and is used to discourage hot fires until other means of control can be brought into effect. The chemical is about ten times as effective as an equal quantity of water.

Spark Arrester Study-During the last two seasons a special study has been made of spark arresters in actual service in logging operations. Two men have been assigned to this work with weather-recording instruments such as an anemometer, hygro-thermograph, rain-gauge, etc. Comparisons have been made with machines operating with and without spark arresters, going into the detail of change of output, if any, under the two conditions. 
An important adjunct to this study has been the publicity given to the necessity for effective spark arresters and the intimate knowledge which the operators have received through observation of the operation of a hygrothermograph and an exposition by the Research Officer of the methods and application of the information recorded.

New Regulations-Following the last season of the legislature, new regulations with respect to logging operations were brought into effect. First it was required that each operating division or camp of not less than 50 men and not more than 200 should have one portable gasoline firefighting pump with 1,000 feet of hose and other necessary equipment. Where the camp or operating division employed more than 200 men, two such pumps with equipment were required.

In the case of each logging donkey under steam where the relative humidity in the vicinity, as shown by a hygro-thermograph, is below sixty per-cent., the ground within 200 feet of the engine must be kept constantly wet by the application of water.

DOMINION FOREST SERVICE.

Fire Patrols-Late winter and early Spring fire patrols in the northern areas of Manitoba and Saskatchewan have been inaugurated.

Due to Mining development in these areas and the resultant heavy traffic, it was considered advisable to check up on the winter and early Spring camp fires.

In Manitoba, this was done by detailing a fire ranger with dog team to patrol the travelled routes, starting early in March and continuing as long as travel was permitted. Fire notices were posted, all traffic met was cautioned, and unattended campfires encountered were extinguished.

In Northern Saskatchewan, a light detection plane, equipped with skis, patrolled the travelled areas and was successful in locating and suppressing numerous fires which would otherwise have continued to smoulder in the muskegs only to break out later in the warm weather and cause considerable damage and expense. Moreover, many of these fires occurred in swamp areas which are inaccessible for fire fighting purposes during summer.

Hitherto, patrols were delayed until open water to permit the use of planes and travel of fire ranging personnel in these northern areas. The experiments of last season with plane and dog team patrol give promise of a future development which may lead to the bridging of the gap between winter conditions and open water.

Plans are now being considered by this Service for an extension of the early spring patrol system with planes.

ONTARIO FORESTRY BRANCH.

Fire Pumps-The R. V. Model, Evinrude Pump has been found most 
convenient for transportation by aircraft to fires where long lines of hose are not required.

Packsack pumps are very satisfactory for mopping up after lầge fires, in extinguishing grass fires and fires in stumps and logs, and for use on brush burning.

Fire Guns-The new model Hauck fire gun is most efficient for starting brush burning fires.

Outboard Motors-Two and one-half horsepower outboard motors are efficient when used on 17 or 18 freight canoes. Where larger canoes are used the four to five horse power motor is required.

Lanterns-Considerable satisfaction has been obtained from a new model Coleman lantern fitted with a pump on the side, also with the Sunlite Senior and the Dewar Lamp No. 206.

Stewart Detectometer-The standard resistance of induction coils, receivers, transmitters, bell coils, etc., being known, any variation from the standard resistance can be located by this instrument. Also, joins on telephone lines can be tested for high resistance.

Protectors-The No. 1079-A.P. protector with No. 80-A mounting and No. 60-A fuses have been found satisfactory in the protection of repeating coils on telephone lines.

Heliograph-During the past season communication by Heliograph was experimented with between two lookout towers fifteen miles apart. The weather was such, however, that a fair trial was not possible. It is believed that under average conditions the service would be satisfactory.

The advantages of the Heliograph are:

(1) Portability,

(2) Simplicity of construction,

(3) Ease of obtaining operators,

(Qualified operators may be secured without trouble from the Department of Militia).

(4) Rapidity of assembly.

Disadvantages:

Cloudy weather.

Wireless Communication-For two seasons wireless communication has been in use in the Red Lake Mining Area between the different headquarters, and last season this means of communication was used in Temagami Reserve between a chief ranger headquarters and a lookout tower 30 miles distant. In all nine stations were in operation, and it is intended to increase this number this season.

While the wireless service was intended primarily for departmental use only it was necessary to assume the reponsibility of public or commercial communication in the Red Lake area. 
Charges on wireless messages to and from the different mining camps where the sets were located were collected, the total revenue averaging about $\$ 1,000$ per month.

Operations of these stations is based on the following factors:

(1) Employment of fully qualified operators to act both as operator and clerk for the Chief or Deputy Chief Ranger.

(2) The use of code.

(3) Simple type of transmitter and receiver.

Power is generated by a gasoline motor primarily designed for farm lighting plants.

The current is supplied through a primary generator to storage batteries. The power and wave lengths are respectively 50 or 75 watts and 50 or 100 meters.

A complete set weighs in the neighborhood of $600 \mathrm{lbs}$. and costs for material $\$ 700$. The sets are assembled by the radio section of the Forestry Branch.

Two battery-operated sets have been constructed for use in providing direct communication between fire fighting crews and headquarters. These sets are built around a $71 / 2$ watt tube and weigh in the neighborhood of $60 \mathrm{lbs}$., with a battery capacity of 12 to 15 hours. On trial they have worked for distances of 200 miles under average radio conditions. They have not actually been tried out on fires.

Landscape Maps - Considerable work has been done in trying to develop a good landscape map for use from lookout towers where intersection is not possible. A map made up of photographs appears to fill the requirements, but the results are not yet entirely satisfactory, although it is believed that a perfect landscape map can be developed.

FOREST PROTECTION SERVICE, QUEBEC.

Fire Pumps-A new type of pump is being tried out which is composed of two separate units weighing respectively 63 and $521 / 2 \mathrm{lbs}$. The two units are carried separately on a special attachment for portaging.

The pump needs practically no grease and is easily adapted to the Johnston outboard motor. It is possible to pump water from any mud hole apparently, as sand, dirt, weeds, gravel, etc., have no effect on the pump.

FOREST SERVICE IN NEW BRUNSWICK.

Fire Finders-A new fire finding instrument, manufactured by Pritchard, Andrews Co., of Ottawa, has been tried out. This consists of an alidade, mounted on a transparent base under which the tower map is placed, a protractor reading from zero to 360 being etched on this transparent base.

Tower Tables-A tower table has been developed which slides on parallel bars in two directions at right angles to each other. 
QUEBEC FOREST INDUSTRIES ASSOCIATION, LTD.

During the season of 1928 a report was made covering an investigation into the meteorological and forest fire hazard conditions in the Province of Quebec.

The purposes of the investigation were:

(1) The making of an estimate of fire hazard on reports furnished by the Meteorological Bureau of Toronto and by the aid of any experiments which might suggest themselves.

(2) To study the possibility of improving weather forecasts and the determining of fire hazard.

(3) To study the useful lines along which research work could be carried out in connection with forest fires.

(4) Collection of statistics, etc.

This report is very complete and I believe may be secured through the Manager of the Association in Quebec City. 